\title{
Reproductive Success of House Wrens in Suburban and Rural Landscapes
}

Author(s): Michael J. Newhouse, Peter P. Marra, L. Scott Johnson

Source: The Wilson Journal of Ornithology, 120(1):99-104.

Published By: The Wilson Ornithological Society

https://doi.org/10.1676/06-156.1

URL: http://www.bioone.org/doi/full/10.1676/06-156.1

BioOne (www.bioone.org) is a nonprofit, online aggregation of core research in the biological, ecological, and environmental sciences. BioOne provides a sustainable online platform for over 170 journals and books published by nonprofit societies, associations, museums, institutions, and presses.

Your use of this PDF, the BioOne Web site, and all posted and associated content indicates your acceptance of BioOne's Terms of Use, available at www.bioone.org/page/terms_of_use.

Usage of BioOne content is strictly limited to personal, educational, and non-commercial use. Commercial inquiries or rights and permissions requests should be directed to the individual publisher as copyright holder. 


\title{
REPRODUCTIVE SUCCESS OF HOUSE WRENS IN SUBURBAN AND RURAL LANDSCAPES
}

\author{
MICHAEL J. NEWHOUSE, $, 1,2,4$ PETER P. MARRA, ${ }^{1,3}$ AND L. SCOTT JOHNSON ${ }^{2}$
}

\begin{abstract}
We investigated the impacts of urbanization on reproductive success of House Wrens (Troglodytes aedon). We compared reproductive effort and success for 33 nesting attempts in suburban sites (2.5-10 buildings/ha) and 43 nesting attempts in rural sites $(<2.5$ buildings/ha) in and around the Washington, D.C.Baltimore, Maryland, metropolitan area. There were no differences in clutch initiation dates or clutch sizes between suburban and rural nests. However, nestlings at suburban nests weighed less and had smaller body size prior to fledging compared to nestlings at rural nests. Parental feeding rates differed between suburban and rural nests during the "early nestling stage" (day 3 to day 6), but not in the "late nestling stage" (day 8 to day 12) suggesting average quality of prey for nestlings may be lower at suburban sites. Overall, suburban nests fledged more young than rural nests largely because of higher rates of nest predation on rural nests. Further research on how food availability and predation affects nesting success of House Wrens and other birds along urbanization gradients may provide important insights into impacts of urbanization on birds. Received 1 November 2006. Accepted 1 April 2007.
\end{abstract}

Land development can directly or indirectly impact native bird populations. For example, development alters habitat thereby reducing available areas for breeding and associated activities. Developed areas can have higher levels of human disturbance (Geise 1996, Beale and Monaghan 2004) and more chemical contaminants than rural areas (Obendorf et al. 2006; K. E. Roux and P. P. Marra, pers. comm.), which can indirectly impact birds through ingestion of contaminated food (e.g., fruit, phytophagous insects). Native bird species often rely on structurally complex habitats with a high proportion of native vegetation for nest sites and food making them particularly vulnerable in developed areas where invasive species often dominate and vegetation structure has been changed drastically (Goldstein et al. 1986, Mills et al. 1991, Case 1996, Pavlik and Pavlik 2000, Hennings and Edge 2003). Finally, as natural areas become fragmented by urbanization the percentage of edge versus interior habitat also increases resulting in birds nesting in edge habitats experiencing higher rates of nest predation

\footnotetext{
${ }^{1}$ Smithsonian Environmental Research Center, Edgewater, MD 21037, USA.

${ }^{2}$ Department of Biological Sciences, Towson University, Towson, MD 21252, USA.

${ }^{3}$ Current address: Smithsonian Migratory Bird Center, National Zoological Park, Washington, D.C. 20008, USA.

${ }^{4}$ Corresponding author; New Jersey Meadowlands Commission, Lyndhurst, NJ 07071, USA; e-mail: michael.newhouse@njmeadowlands.gov
}

(Robinson et al. 1995, Donovan et al. 1997, Donnelly 2002, Donnelly and Marzluff 2004).

Despite the challenges that affect birds in developed environments, habitats in urban/ suburban areas may attract birds by presenting them with historically reliable cues to suitable nesting habitat. Patches of apparently suitable breeding habitat that remain in developed environments may become "ecological traps" (i.e., habitats that lure birds to settle, but result in lower overall fitness) (Gates and Gysel 1978, Purcell and Verner 1998, Donovan and Thompson 2001, Kokko and Sutherland 2001, Schlaepfer et al. 2002, Weldon and Haddad 2005). Developed areas may be population sinks-areas occupied by breeding birds but with individuals producing too few surviving young to sustain the local population (e.g., Misenhelter and Rotenberry 2000, Resumeš 2000).

Few studies have examined the impacts of urbanization on bird reproductive success and on individual fitness. Most research has examined how rates of nest depredation vary along urban to rural land-use gradients or with increasing forest fragmentation (e.g., Robinson et al. 1995, Patten and Bolger 2003). The general conclusion from these studies is that depredation increases with proximity to forest edge. Leston and Rodewald (2006) examined reproductive success of Northern Cardinals (Cardinalis cardinalis) in forests within urban and suburban land-use types; they found these sites provided suitable breeding habitat and 
were not ecological traps. However, response to the effects of urbanization may vary between species.

We examined the reproductive success of House Wrens (Troglodytes aedon) nesting in the rural and suburban habitat matrix. Our primary objective was to ascertain whether suburban development negatively impacted reproductive success of this cavity-nesting species. House Wrens are well-suited for study of the impacts of development on reproductive success because they prefer open woodlands and readily nest in suburban areas.

\section{METHODS}

Study Species.-House Wrens are small (10-12 g), migratory, insectivorous, secondary cavity-nesting songbirds that breed across much of North America (Johnson 1998). This species nests naturally in pre-formed tree cavities but readily uses nest boxes. Females normally produce two broods each season, laying 6-8 eggs for first breeding attempts and 4-7 eggs for second attempts. Only females brood young but both adults feed nestlings.

Study Sites and Nest Box Examination.We conducted this study during spring and summer 2004 in and around the Washington, D.C.-Baltimore, Maryland, metropolitan area. The Washington, D.C. area has experienced a five-fold increase in human population density during the last century from 1.1 million residents in 1900 to approximately 5.3 million in 2000 (Negative Population Growth 2005).

In this study, 202 of 210 nest boxes available to wrens were on properties (i.e., yards) owned by participants in the Neighborhood Nestwatch Program. This project is operated by the Smithsonian Migratory Bird Center (SMBC) of the National Zoological Park (http://www.fonz.org/nestwatch.htm). We classified properties as suburban or rural based on the density of human dwellings in the area surrounding a nest site (Cam et al. 2000, Marzluff 2001, Thorington and Bowman 2003). We followed Marzluff (2001) and classified the habitat surrounding a nest as suburban if it had 2.5-10 dwellings/ha and rural if there were $\leq 2.5$ dwellings/ha.

Several landowners had existing nest boxes and we added 65 additional nest boxes to properties prior to start of our study, distributing them equally between suburban and ru- ral habitats. All added nest boxes were suspended from trees approximately $2.5-3.0 \mathrm{~m}$ above ground and were not equipped with predator deterrent devices. Ultimately, each site contained an average of three nest boxes. Of the eight nests that were not part of the Nestwatch program, seven were at environmental education centers in rural Maryland while one was in a suburban neighborhood. Three of 91 boxes (3\%) in suburban habitats and 83 of 119 boxes $(69 \%)$ in rural habitats had predator deterrent devices.

We checked nest boxes every 4-5 days beginning in mid-April until males present had paired. Thereafter, we visited each nest every other day to identify dates on which the first eggs were laid (all dates are reported as Julian dates). Female House Wrens usually lay one egg/day. We captured adults with mist nets and marked them with a USGS numbered aluminum leg band and two colored bands. Males were captured after pairing. Females were not captured until their eggs had hatched to reduce risk of nest abandonment. No nests were abandoned immediately after female capture.

We visited nest boxes 7-10 days after the first egg was laid to measure clutch size. We did not check nests daily after laying began and could not compare rates of partial clutch loss in suburban and rural habitats. We checked nests daily starting 11 days after laying ended to identify the day that hatching began. We termed the date of hatching Nestling Stage Day (NSD) 0. We banded, weighed nestlings, and measured both their wing chord and tarsus to the nearest $0.01 \mathrm{~mm}$ on NSD 11 .

We recorded the number of young fledged from a nest as the number of young present on NSD 11 minus the number of young found dead in the nest after fledging. We considered a nesting attempt successful if $\geq 1$ nestling fledged from the nest. All nests that failed appeared to do so as a result of abandonment, depredation, conspecific nest destruction, or hypothermia. There were no nests in which nestlings disappeared gradually or as a result of apparent starvation. We assumed parental abandonment when eggs were present but unattended. We assumed abandonment or hypothermia when all nestlings were found dead in the nest. We assumed predation when eggs or nestlings were missing and nest contents 
were substantially disturbed. We also assumed predation when nest contents were not disturbed, eggs or young had disappeared, and the nest had not been occupied by a new male. Finally, we assumed conspecific nest destruction had occurred when the nest was largely intact, all eggs or nestlings were missing from the nest, and a new male had occupied the nest.

Parental Provisioning Behavior-We recorded the number of trips made by parents to deliver food to nestlings for one continuous hour between the 0700 and 1100 hrs EST. We monitored nests with binoculars from a distance of 15-20 m. Data collection began when both parents appeared to be accustomed to our presence (typically about $5 \mathrm{~min}$ ). We documented provisioning rates at two points during the nestling stage, "early" (NSD 2 to NSD 6, $n=16$ ) and "late" (NSD 8 to NSD 12, $n=$ $24)$. Some nests $(n=11)$ were observed during both early and late nestling stages. Adults typically deliver a single prey item per trip; thus, the number of provisioning trips generally equals the number of prey items transported to the nest (Morrison and Johnson 2002). We also documented the total time that females spent brooding young. We assumed that time in the nest box $>1$ min involved brooding. All observations were at a similar time of season.

We observed two parents provisioning nestlings at most nests during the early nestling stage including 9 of 10 suburban and 7 of 11 rural nests. Only females were provisioning at the remaining nests. In contrast, we observed only one parent provisioning at 10 of 15 suburban nests (eight females, two males) and 9 of 10 rural nests (seven females, two males) during the latter part of the nestling stage. Desertion of the nest by one parent, usually the male, is not uncommon in House Wrens (Czapka and Johnson 2000). Our intent was to use provisioning rates as an index of prey availability as the number of parents provisioning at a nest will influence feeding rates. Thus, we included only those early stage observations in which two parents were provisioning and only those late-stage observations with only one parent provisioning in our analysis.

Statistical Analyses.-We compared the mean date the first egg was laid in the first 15 nests of the season in the two habitat types using a $t$-test to examine whether onset of breeding differed in suburban and rural habitats. We used analysis of covariance (ANCOVA) with date of first egg as a covariate to compare clutch size. We report leastsquares means adjusted for effects of laying date. We used the same analysis to compare the number of young fledged from successful nests. We could not use ANCOVA to compare number of young fledged from all nests, successful and unsuccessful, because data were not normally distributed. Therefore, we compared numbers of fledglings from all nests using a Wilcoxon Rank Sum test. We used the same test to compare number of fledglings per egg laid. We compared measures of nestling mass and size using a $t$-test, using mean brood values to avoid pseudoreplication. Broods tended to be smaller in rural nests and we also compared nestling measures using ANCOVA with brood size as a covariate and report leastsquares means adjusted for brood size. We report interactions only if significant. We report means \pm SE unless otherwise noted. All statistical analyses were performed using SAS Version 8.1 (SAS Institute 1999).

\section{RESULTS}

We monitored reproduction at 76 nests (Table 1), 33 in suburban areas (17 first and 16 second broods) and 43 in rural habitats (24 first and 19 second broods). Birds in suburban and rural areas commenced breeding at the same time and laid similarly sized clutches. However, House Wrens in rural habitats were less successful $(P<0.001)$ at fledging at least one nestling than those in suburban habitats (60 vs. $88 \%$ of nests, respectively). Seven of the $17(41 \%)$ unsuccessful nests in rural habitats were most likely destroyed by snakes and the remaining 10 were either destroyed by predators or by conspecifics. We could not clearly assign cause of failure in two of the four cases where nests failed in suburban habitats. In the remaining two cases, the entire brood was found dead suggesting either abandonment or death from hypothermia. A greater proportion of nests in rural compared to suburban habitats were destroyed by predators ( 0 vs. $41 \% ; \chi^{2}=3.69, P=0.05$ ). This explains, in part, why rural nests fledged significantly fewer young per nest, on average, than 


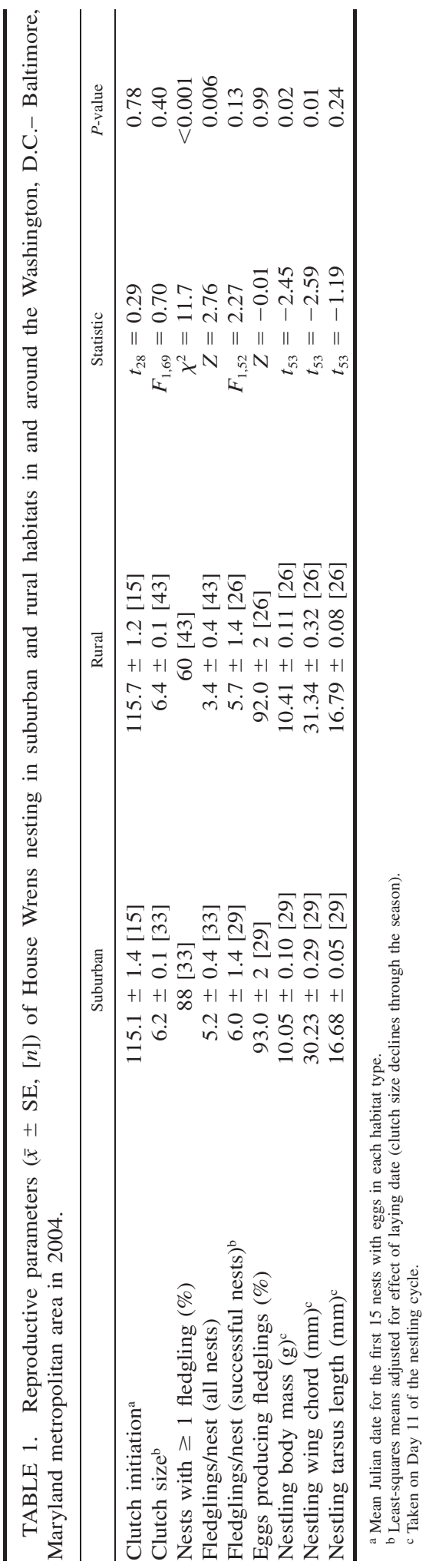

suburban nests. Successful rural nests did not produce fewer fledglings than suburban nests after adjusting for seasonal effects on fledgling production. The mean number of fledglings per egg laid was also nearly identical for successful rural and suburban nests.

The mean mass of nestlings on NSD 11 was greater in rural nests than in suburban nests $(P<0.02)$. The difference in nestling mass was significant even after controlling for brood size which were, on average, smaller in rural nests $\left(F_{1,52}=4.67, P<0.04\right)$. Similarly, nestlings had longer wing chords, on average, on NSD 11 in rural compared to suburban nests, even after controlling for brood size $\left(F_{1,52}=5.97, P<0.02\right)$. Tarsus length of nestlings in rural and suburban nests did not differ.

House Wren pairs early in the nestling stage delivered prey at a greater $(P<0.01)$ rate at suburban nests than at nests in rural areas (Table 2). In contrast, we found no difference in the rate at which parents provisioned older nestlings in suburban and rural habitats. Females at rural nests spent more time brooding nestlings than females at suburban nests $(P<$ 0.02; Table 2). Brooding time declined as provisioning rates increased in both habitats $(r=$ $-0.56, n=14, P=0.03$ ).

\section{DISCUSSION}

Reproductive success of House Wrens nesting in rural and suburban habitats varied with lower fledging success in rural habitats because of greater rates of nest predation. Our results, however, were mixed. Nestlings reared in suburban areas weighed significantly less and had shorter wings compared to nestlings reared in rural areas. In an Illinois population of House Wrens, a nestling's probability of being recruited into the breeding population was positively associated with its body mass late in the nestling stage (C. F. Thompson, unpubl. data). Similar results have been reported for several species (Newton 1998).

Our result that nests in rural areas were depredated at significantly higher rates compared to nests in suburban areas was striking given that far more rural than suburban nest boxes had predator-deterrent devices (69 vs. 3\% of nest boxes, respectively). Rural nests may have been depredated significantly more often because most nest boxes were on the edge of large forest fragments facing more open land- 
TABLE 2. Parental behavior $(\bar{x} \pm \mathrm{SE},[n])$ of House Wrens nesting in suburban and rural habitats in the Washington, D.C.-Baltimore, Maryland metropolitan area in 2004.

\begin{tabular}{lcccr}
\hline & \multicolumn{1}{c}{ Suburban } & \multicolumn{1}{c}{ Rural } & Statistic & $P$-value \\
\hline Feeding rate, early $^{\mathrm{a}}$ & $3.2 \pm 0.3[9]$ & $2.0 \pm 0.2[7]$ & $t_{14}=-3.31$ & $<0.01$ \\
Feeding rate, late $^{\mathrm{b}}$ & $4.0 \pm 0.57[10]$ & $3.40 \pm 0.6[9]$ & $t_{17}=-0.79$ & 0.44 \\
Minutes brooding/hr & $29.0 \pm 4[8]$ & $43.0 \pm 6[6]$ & $t_{12}=2.81$ & $<0.02$ \\
\hline
\end{tabular}

a Provisionings/nestling/hr, 1-4 days post-hatching.

b Provisionings/nestling/hr, 9-13 days post-hatching.

scapes. Edge habitats are known to have higher numbers of predators (e.g., Patten and Bolger 2003). Most rural nest boxes were older and had been in place longer than the suburban nest boxes, giving predators the chance to learn nest locations and how to elude predator deterrent devices.

Differences in nestling body mass (Table 1) between habitats may be caused by differences in prey quantity or quality. We have no data to address this hypothesis directly and are unaware of existing data directly relevant to birds. Parents in suburban habitats appeared to deliver as many or more prey to nests compared to parents in rural habitats and yet produced lighter, smaller offspring; this suggests that prey quality may be lower in suburban areas. Consistent with this observation are the findings of Ishitani et al. (2003) who reported that insects in suburban habitats tend to be smaller than species in more natural habitats. Females in suburban habitats also spent less time brooding nestlings during our watches. We did not observe any human disturbance while watching nests in both habitats. Nestlings in suburban areas may grow more slowly because lower body temperatures cause them to process food less efficiently and invest more energy in thermoregulation at the expense of growth (Johnson and Kermott 1993, Dawson et al. 2005).

Highly disturbed environments, such as residential suburban habitats, may represent an ecological trap for some species. Leston and Rodewald (2006) failed to find any differences in reproductive success or apparent survival of Northern Cardinals breeding in forest patches within urban versus rural landscapes. Our finding that House Wrens in suburban habitats produce lighter, smaller offspring suggests these habitats may act as ecological traps. However, counter to this suggestion is the finding that suburban nests also experi- enced significantly lower rates of nest predation. Further work is needed to learn whether this result is an artifact of our use of nest boxes. House Wrens are common in suburban habitats which suggest sufficient young are produced in these habitats to sustain populations. Alternatively, suburban habitats may be sinks and populations rely on dispersal of individuals from other locations to maintain current densities. Research quantifying factors directly associated with habitat quality (e.g., prey availability and nest predation rates), measures of annual survival, and habitat selection in this system should provide insight into the extent urban and suburban areas act as population sinks and ecological traps for House Wrens and other native song birds.

\section{ACKNOWLEDGMENTS}

We thank the Neighborhood Nestwatch participants for permission to work on their property, J. Smith, R. J. Peters, and K. E. Roux for help in the field, and R. $\mathrm{S}$. Ebersole for valuable comments on the manuscript and moral support. We also thank the Mills Corporation for financial support.

\section{LITERATURE CITED}

Beale, C. M. and P. Monaghan. 2004. Human disturbance: people as predation free predators? Journal of Applied Ecology 41:335-343.

Cam, E., J. D. Nichols, J. R. SAuer, J. E. Hines, And C. H. Flather. 2000. Relative species richness and community completeness: birds and urbanization in the Mid-Atlantic States. Ecological Applications 10:1196-1210.

CASE, T. J. 1996. Global patterns in the establishment and distribution of exotic birds. Biological Conservation 78:69-96.

Czapka, S. J. And L. S. Johnson. 2000. Consequences of mate sharing for first-mated females in a polygynous songbird, the House Wren. Wilson Bulletin 112:72-81.

Dawson, R. D., C. C. Lawrie, And E. L. O'Brien. 2005. The importance of microclimate variation in determining size, growth and survival of avian 
offspring: experimental evidence from a cavity nesting passerine. Oecologia 144:499-507.

DonNelly, R. 2002. Design of habitat reserves and settlement for bird conservation in the Seattle metropolitan area. Dissertation. University of Washington, Seattle, USA.

DonNelly, R. AND J. M. MARZLuFF. 2004. Importance of reserve size and landscape context to urban bird conservation. Conservation Biology 18:733-745.

Donovan, T. M. AND F. R. ThOMPSON. 2001. Modeling the ecological trap hypothesis: a habitat and demographic analysis for migrant songbirds. Ecological Applications 11:871-882.

Donovan, T. M., P. W. Jones, E. M. Annand, AND F. R. Thompson. 1997. Variation in local-scale edge effects: mechanisms and landscape context. Ecology 78:2064-2075.

Gates, J. E. AND L. W. Gysel. 1978. Avian nest dispersion and fledging success in field-forest ecotones. Ecology 59:871-883.

GIESE, M. 1996. Effects of human activity on Adelie Penguin Pygoscelis adeliae breeding success. Biological Conservation 75:157-164.

Goldstein, E. L., M. Gross, and R. M. DeGraff. 1986. Breeding birds and vegetation: a quantitative assessment. Urban Ecology 9:377-385.

Hennings, L. A. AND W. D. Edge. 2003. Riparian bird community structure in Portland, Oregon: habitat, urbanization, and spatial scale patterns. Condor 105:288-302.

Ishitani, M., D. J. Kotze, and J. Niemela. 2003. Changes in carabid beetle assemblages across an urban-rural gradient in Japan. Ecography 26:481489.

Johnson, L. S. 1998. The House Wren (Troglodytes aedon). The birds of North America. Number 380.

Johnson, L. S. AND L. H. Kermott. 1993. Why is reduced male parental assistance detrimental to the reproductive success of secondary female House Wren? Animal Behaviour 46:1111-1120.

Kokko, H. AND W. J. Sutherland. 2001. Ecological traps in changing environments: ecological and evolutionary consequences of a behaviourally mediated Allee effect. Evolutionary Ecology Research 3:537-551.

Leston, L. And A. D. Rodewald. 2006. Are urban forests ecological traps for understory birds? An examination using Northern Cardinals. Biological Conservation 131:566-574.

MARZlufF, J. M. 2001. Worldwide urbanization and its effects on birds. Pages 19-47 in Avian ecology and conservation in an urbanizing world (J. M. Marzluff, R. Bowman, and R. Donnelly, Editors). Kluwer Academic, Norwell, Massachusetts, USA.
Mills, G. S., J. B. Dunning JR., And J. M. Bates. 1991. The relationship between breeding bird density and vegetation volume. Wilson Bulletin 103: 468-479.

Misenhelter, M. D. And J. T. Rotenberry. 2000. Choices and consequences of habitat occupancy and nest site selection in Sage Sparrows. Ecology 81:2892-2901.

Morrison, B. L. AND L. S. JoHnSOn. 2002. Feeding of House Wren nestlings afflicted by hematophagous ectoparasites: a test of the parental compensation hypothesis. Condor 104:183-187.

Negative Population Growth. 2005. Maryland's population in 2050: is smart growth enough? http://www.npg.org/polls091200/md (accessed 22 June 2005).

Newton, I. 1998. Population limitation in birds. Academic Press. London, United Kingdom.

Obendorf, S. K., A. T. Lemley, A. Hedge, A. A. Kline, K. TAN, And T. Dokuchayeva. 2006. Distribution of pesticide residues within homes in central NY State. Archives of Environmental Contamination and Toxicology 50:31-44.

Patten, M. A. and D. T. Bolger. 2003. Variation in top-down control of avian reproductive success across a fragmentation gradient. Oikos 101:479488.

Pavlik, J. And S. PaVlik. 2000. Some relationships between human impact, vegetation, and birds in urban environments. Ekologia-Bratislava 19:392408.

Purcell, K. L. And J. Verner. 1998. Density and reproductive success of California Towhees. Conservation Biology 12:442-450.

Resumeš, V. 2000. How can maladaptive habitat choice generate source-sink population dynamics? Oikos 91:579-582.

Robinson, S. K., F. R. Thompson III, And T. M. DonOVAN. 1995. Regional forest fragmentation and the nesting success of migratory birds. Science 267: 1987-1990.

SAS InSTITUTE. 1999. SAS/STAT user's guide. Release 8.1. SAS Institute Inc., Cary, North Carolina, USA.

Schlaepfer, M. A., M. C. Runge, And P. W. Sherman. 2002. Ecological and evolutionary traps. Trends in Ecology and Evolution 17:474-480.

Thorington, K. K. And R. Bowman. 2003. Predation rate on artificial nests increases with human housing density in suburban habitats. Ecography 26: 188-196.

Weldon, A. J. AND N. M. HAdDAD. 2005. The effects of patch shape on Indigo Buntings: evidence for an ecological trap. Ecology 86:1422-1431. 